\title{
Magnetic resonance imaging evidence for perineural spread of endometriosis to the lumbosacral plexus: report of 2 cases
}

\author{
*Ana C. Siquara de Sousa, MD,, Stepan Capek, MD, ${ }^{1,5}$ Benjamin M. Howe, MD, ${ }^{2}$ \\ Mark E. Jentoft, MD, ${ }^{3}$ Kimberly K. Amrami, MD, ${ }^{2}$ and Robert J. Spinner, MD ${ }^{1}$ \\ Departments of ${ }^{1}$ Neurosurgery, ${ }^{2}$ Radiology, and ${ }^{3}$ Anatomic Pathology, Mayo Clinic, Rochester, Minnesota; ${ }^{4}$ Department of \\ Anatomic Pathology, Gaffrée e Guinle University Hospital, Rio de Janeiro, Brazil; and 5International Clinical Research Center, \\ St. Anne's University Hospital Brno, Czech Republic
}

\begin{abstract}
Sciatic nerve endometriosis (EM) is a rare presentation of retroperitoneal EM. The authors present 2 cases of catamenial sciatica diagnosed as sciatic nerve EM. They propose that both cases can be explained by perineural spread of EM from the uterus to the sacral plexus along the pelvic autonomic nerves and then further distally to the sciatic nerve or proximally to the spinal nerves. This explanation is supported by MRI evidence in both cases. As a proof of concept, the authors retrieved and analyzed the original MRI studies of a case reported in the literature and found a similar pattern of spread. They believe that the imaging evidence of their institutional cases together with the outside case is a very compelling indication for perineural spread as a mechanism of EM of the nerve.
\end{abstract}

http://thejns.org/doi/abs/10.3171/2015.6.FOCUS15208

KEY WORDS endometriosis; sciatic nerve; sciatica; magnetic resonance imaging; autonomic pathways

$\mathrm{E}$ NDOMETRIOSIS (EM) is a common gynecological disease that affects the endometrial glands and stroma outside the uterine cavity, mainly in the peritoneum, ovaries, and rectovaginal septum. It affects nearly 5\%$10 \%$ of women in their reproductive years (ages 15-49 years), and its annual incidence is $0.1 \%{ }^{6,48} \mathrm{EM}$ commonly presents with pelvic pain but can produce sciatic, obturator, or femoral nerve symptoms. Although the first histologically proven case was described in 1955 by Denton and Sherrill ${ }^{17}$ and more than a hundred of such cases have since been reported, the mechanism of nerve involvement with EM remains enigmatic. We present 2 cases of EM with sciatic neuropathy. We hypothesize that involvement of the lumbosacral plexus (LSP) in selected cases can be explained by perineural spread of EM from the uterus to the LSP along the pelvic autonomic nerves. We prove that our theory is applicable to other cases by testing this theory in a case reported in the literature.

\section{Part I: Institutional Case Reports Case 1 \\ Presentation}

A 49-year-old woman was referred to our institution in June 2013 with a diagnosis of lumbosacral plexopathy of unknown etiology. Her relevant medical history was significant for a ureteral stricture and cervical and lumbar spine degenerative disease. She had no history of EM.

History

Her symptoms started in October 2011 after she lifted a heavy object. She developed low-back pain radiating to the left buttock. Over subsequent months she gradually developed left lower-extremity weakness and numbness.

MRI of the lumbar spine done in May 2012 failed to reveal any significant abnormalities. MRI of the pelvis (Fig. 1) performed in October 2012 demonstrated an amorphous

ABBREVIATIONS DIE = deep infiltrating endometriosis; EM = endometriosis; IHP = inferior hypogastric plexus; LSP = lumbosacral plexus.

SUBMITTED April 29, 2015. ACCEPTED June 16, 2015.

INCLUDE WHEN CITING DOI: 10.3171/2015.6.FOCUS15208.

* Drs. Siquara de Sousa and Capek contributed equally to this work. 

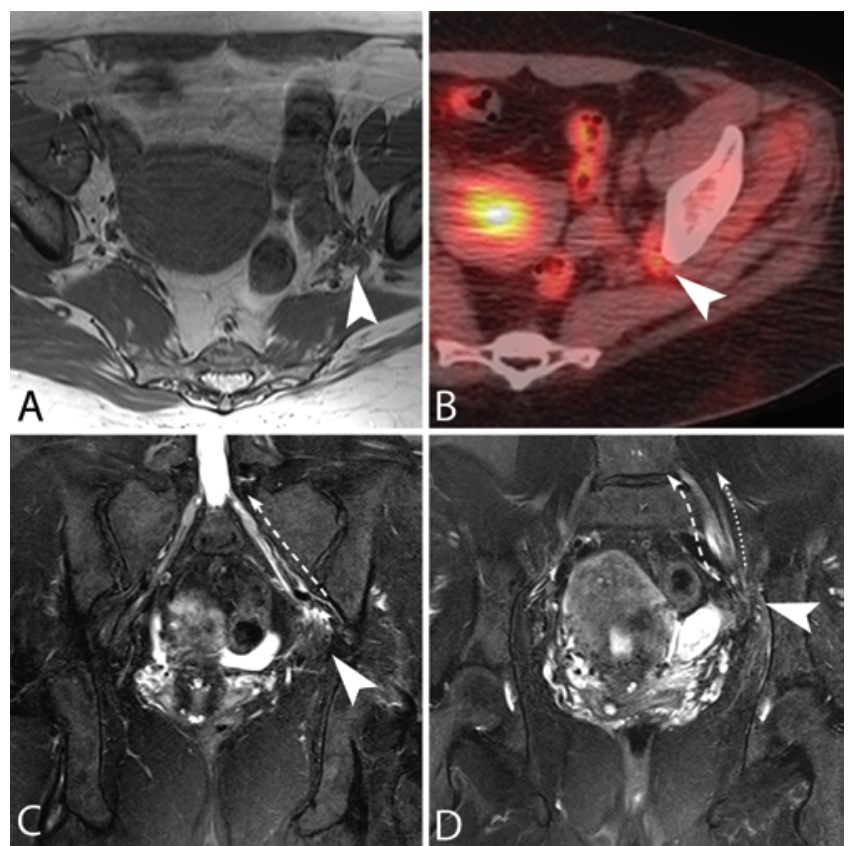

FIG. 1. Case 1. 2012 MRI and PET/CT studies. A T1-weighted axial image (A) demonstrates an enlarged left sciatic nerve associated with a spiculated soft-tissue mass with hyperintense areas suggestive of intralesional bleeding (arrowhead). A composite axial FDG PET/CT image (B) shows increased uptake compared with surrounding musculature in the area corresponding to the left sciatic nerve (arrowhead). A coronal oblique T2-weighted fat-saturated image (C) demonstrates a hyperintense left S-1 spinal nerve with an area of abnormality (dashed arrow) extending along the nerve from a heterogeneous spiculated mass (arrowhead) proximally through the S-1 sacral foramen. A coronal oblique T2-weighted fat-saturated image (D) shows similarly increased signal in the left L-4 (dotted arrow) and L-5 (dashed arrow) spinal nerves proximal to the soft-tissue mass (arrowhead).

enhancing soft-tissue mass, thought to represent scar tissue or other granulation tissue, at the sciatic notch associated with the L-5 and S-1 spinal nerves. The mass extended along the L4-S1 spinal nerves proximally. The nerve themselves were hyperintense on T2-weighted images and enhancing on postcontrast scans. The gluteal musculature showed signs of acute and chronic denervation. PET/CT studies from October 2012 demonstrated an area of increased uptake at the sciatic notch compared with the surrounding normal musculature (Fig. 1B).

\section{Examination}

On neurological examination the patient had a left foot drop with markedly reduced strength in the left anterior tibialis (Grade 1/5), toe extensor (Grade 1/5), and peronei muscles (Grade 0/5). Her sensory examination showed reduction to pin and light touch over the left lateral calf and medial foot, with a qualitative sensation alteration to pin in the lateral foot and posterior thigh.

Electromyography conducted in June 2013 revealed a left lumbosacral plexopathy affecting the L-5 and S-1 myotomes associated with active denervation.

MRI of the LSP performed at the same time (Fig. 2), with and without intravenous contrast material, showed an ill-defined and slightly spiculated soft-tissue mass as- sociated with the sciatic nerve at the sciatic notch. The mass itself was heterogeneous on T1- and T2-weighted sequences with cystic areas. Post-Gd scans demonstrated linear abnormality extending from the body of the uterus to the LSP or sciatic nerve proximal to the sciatic notch. The nerve itself appeared to be enlarged and infiltrated by the mass. A lesion with similar characteristics was discovered in the left obturator internus muscle. The gluteal musculature and obturator internus muscle exhibited signs of chronic denervation.

\section{Procedure}

A fine-needle aspiration biopsy of the lesion (Fig. 2F) was performed and revealed epithelial tissue with scant stroma positive for estrogen receptors (glands and stroma) and CD10 (stroma) (Fig. 3). The diagnosis of EM was established.

\section{Postoperative Course}

The patient was started on hormonal therapy. On follow-up 6 months later the patient reported resolution in pelvic pain and improved cyclic gluteal pain.

\section{Case 2}

\section{Presentation}

A 32-year-old woman with no relevant medical history presented to our institution in November 2000 with catamenial low-back, hip, and right lower-extremity pain accompanied by tingling in the distal leg.

\section{History}

Initially, in the fall of 1998 the patient noticed mild hip and pelvic pain, and numbness and tingling in the right lower extremity associated with her menstrual cycles. These symptoms progressively worsened.

MRI of the pelvis from February 2000 showed increased T2 signal along the right lateral pelvic wall involving the obturator internus and piriformis muscles. Changes were noted to be consistent with an inflammatory process and EM was suspected; however, a discernible endometrioma was not identified.

In March 2000 the patient underwent laparoscopy, which revealed peritoneal EM. She was started on gonadotropin-releasing hormone agonist treatment and experienced complete resolution of the pain. This therapy was discontinued after 4 months due to side effects, and the symptoms returned.

\section{Examination}

Electromyography done in November 2000 confirmed right sciatic neuropathy proximal to the innervation of the medial hamstrings. The abnormalities in the lumbar paraspinal muscles suggested involvement of the LSP.

MRI of the pelvis performed in November 2000 (Fig. 4) demonstrated a massively enlarged right sciatic nerve at the sciatic notch, which was hyperintense on T1- and T2-weighted sequences and heterogeneously enhancing on post-Gd scans. A similar heterogeneous abnormality with hemosiderin depositions was noted to be in the right piriformis and obturator internus muscles and in the right 

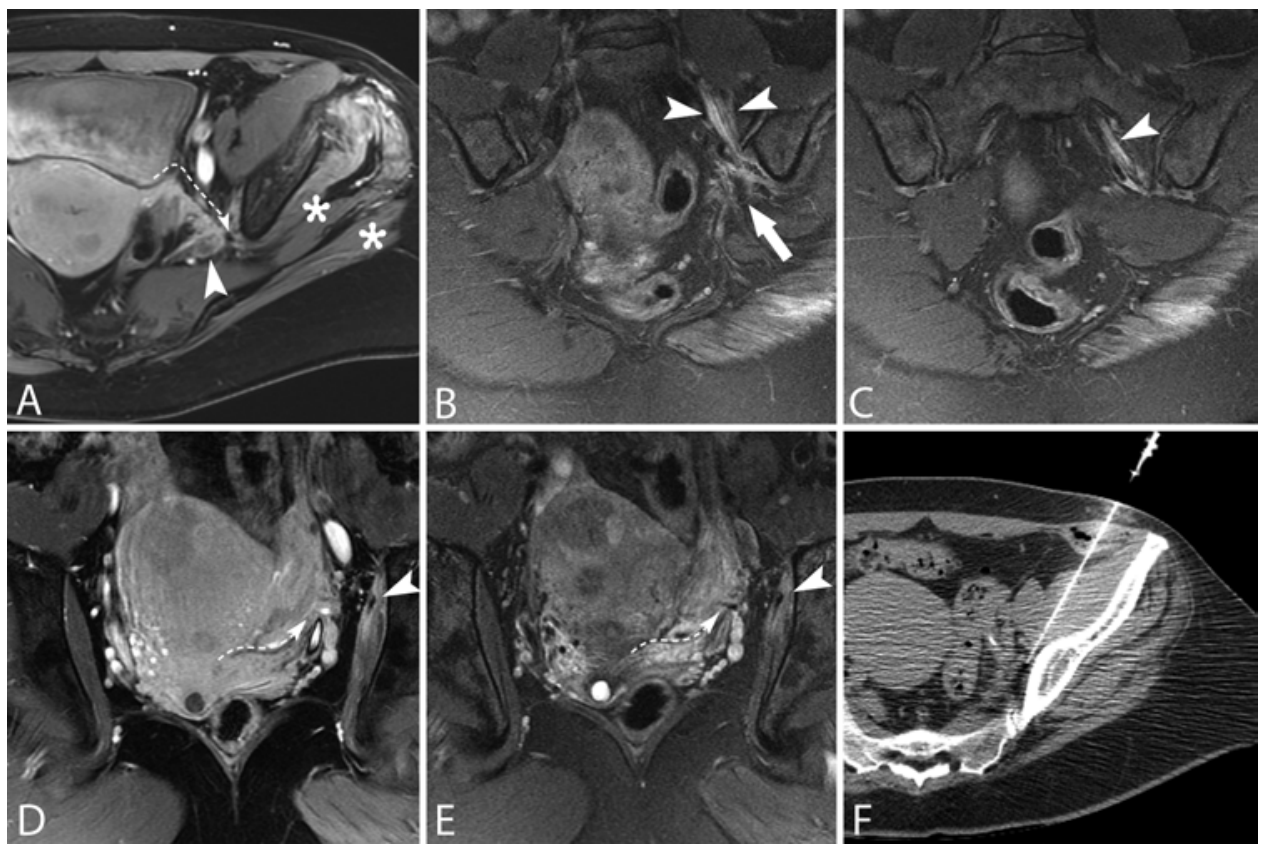

FIG. 2. Case 1. 2013 MRI. An axial spoiled gradient recall (SPGR) Gd-enhanced image (A) demonstrates an area of enhancing abnormality (dashed arrow) extending from the body of the uterus to the left LSP and left sciatic nerve, which is markedly enlarged and appears to be infiltrated by the abnormality (arrowhead). The gluteal musculature is atrophic (asterisks). A coronal oblique T2-weighted image (B) shows increased signal of the L-4 and L-5 spinal nerves (arrowheads) proximal to an area of spiculated hyperintense soft-tissue mass (arrow). Increased signal on a T2-weighted image (C) is also demonstrated by the left S-1 spinal nerve (arrowhead). A coronal oblique SPGR image (D) demonstrates enhancing lesion with center area of decreased signal in the upper portion of the left obturator internus muscle (arrowhead) and an abnormally enhancing and heterogeneous left uterosacral ligament, possibly representing extension of endometrial tissue from the cervix to the inferior hypogastric plexus (dashed arrow). The same lesions were hyperintense on a T2-weighted coronal image (E: arrowhead and dashed arrow), the central area presumably representing hemosiderin collection. A CT-navigated biopsy (F) of the soft-tissue mass in close vicinity of the LSP was performed and revealed endometriosis.

ischium. Based on the signal characteristics, these lesions were concluded to be foci of EM.

\section{Treatment}

EM was confirmed as the etiology based on the positive response to the gonadotropin-releasing hormone agonist, which the patient was started on in 2001. On follow-up 5 years later, the patient reported mild residual pelvic pain, no radiating pain, and improved ability to walk longer distances. MRI performed in 2005 demonstrated near-complete resolution of EM (Fig. 4D).

\section{Part II: Retrospective Reinterpretation of a Previously Published Case}

We wondered if our theory would apply to other cases in the literature. As a proof of concept, we retrieved a case reported by colleagues (Domínguez-Páez et al. ${ }^{18}$ ) of a patient with right sciatic nerve EM. We reviewed the most recent MR images (2014) and MR images obtained 3 years earlier (2011). On the MRI from 2011 the sciatic nerve was massively enlarged and surrounded by heterogeneous tissue with focal hemorrhages suggestive of EM. As in our case we could follow the abnormality extending from the cervix to the right LSP, which also had similar imaging characteristics (Fig. 5A and B). On the 2014 MRI the sciatic nerve decreased in size, although it was still enlarged compared with its normal size as well as the L4-S1 spinal nerves. The spinal nerves (Fig. 5C and D) appeared identical to those in our Case 1 (Fig. 1C and D). We believe this case indeed represents another example of perineural spread of EM and further strengthens our theory.

\section{Discussion}

We propose that perineural spread from the organ to the LSP, demonstrated in pelvic cancer ${ }^{1,11,22}$ including cervical cancer, ${ }^{25}$ applies to EM as well and represents an alternate mechanism in selected cases. The possibility of EM tracking along the nerves as a form of spread was described by Possover et al. ${ }^{37}$ however, such an anatomical, mechanistic explanation as the one described in the present report has not yet been postulated. We provide compelling evidence by presenting our 2 cases and the previously published case $\mathrm{e}^{18}$ that showed signs of perineural spread.

We hypothesize that endometrial glands and stroma infiltrate the uterine plexus, part of the inferior hypogastric plexus (IHP). From the IHP, EM continues to grow toward the sacral plexus along the sacral and pelvic splanchnic nerves and toward the lumbar plexus along the hypogastric nerves (Fig. 6). Within the plexus, EM can spread proximally to the spinal nerves (Figs. $1 \mathrm{C}$ and D and 5C and D) or distally to the arborizing nerves. We were surprised by the presence of EM in the pelvic muscles (Figs. 2D and E and $4 \mathrm{~A}$ and $\mathrm{B}$ ) and pelvic bone (Fig. 4A and B) in a pattern similar to that which has been described for perineu- 

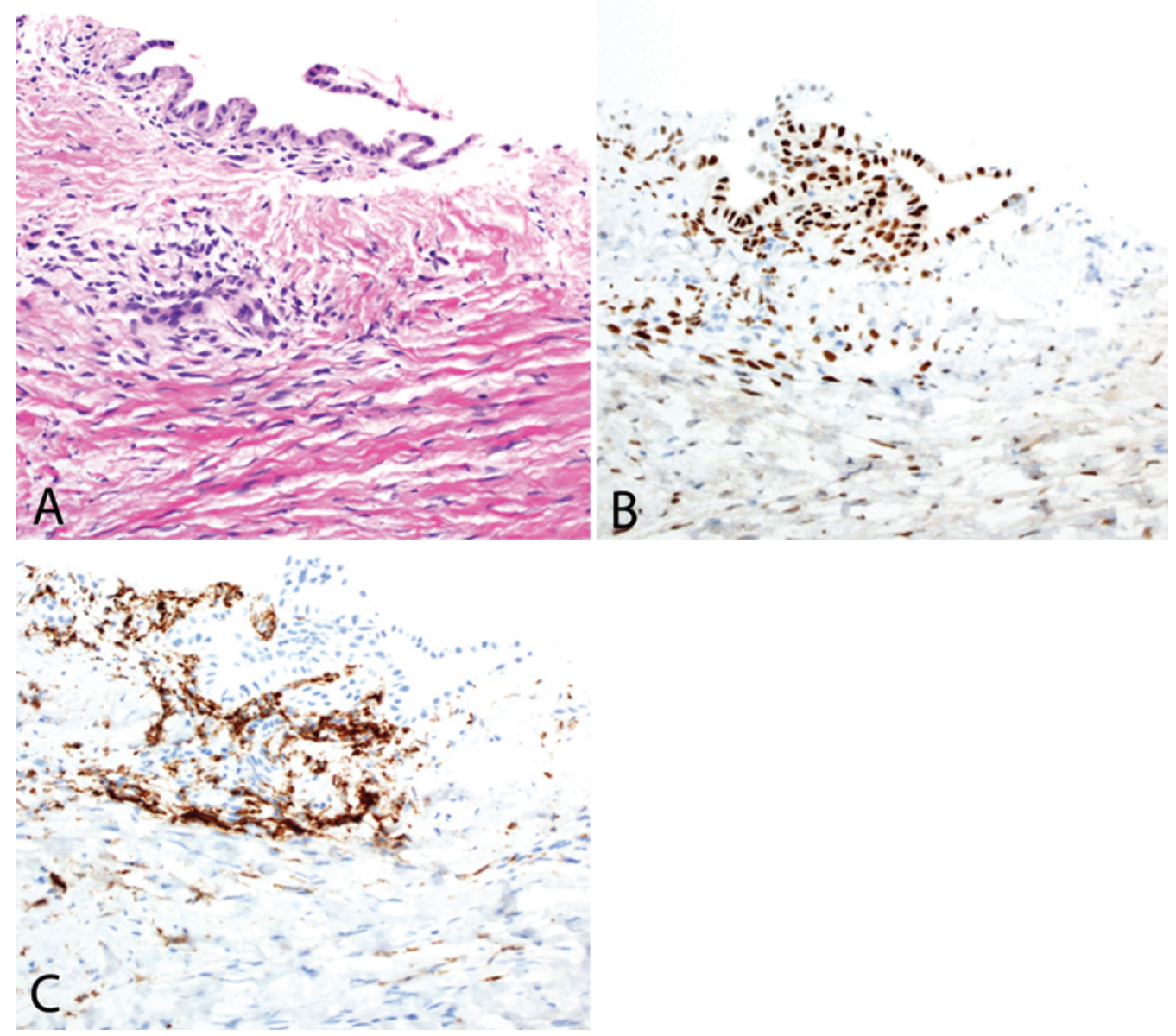

FIG. 3. Case 1. Pathology. A: A single benign-appearing gland is present with minimal underlying stroma. $H \& E$, original magnification $\times 200$. B: The gland and scant underlying stroma are positive for estrogen receptors. Estrogen receptor immunohistochemistry, original magnification $\times 200$. C: The stroma is also positive for CD10. Original magnification $\times 200$. These staining patterns in conjunction with the morphology support the diagnosis of endometriosis.

ral spread of malignant cancer to muscle ${ }^{8}$ and bone. ${ }^{9}$ We theorize that these deposits could result from perineural spread of EM along the motor and bone branches from the LSP.

How EM invades the uterine plexus is not clear. Up to $90 \%$ of women with $\mathrm{EM}^{6}$ have adenomyosis, and deep adenomyotic nodules have been demonstrated to be closely associated with nerves. ${ }^{5}$ We theorize that endometriotic cells and stroma can propagate from deep adenomyotic nodules along the fine uterine nerves toward the IHP in the uterosacral ligament (Fig. 2D and E) and then as described above. The perineural spread as a possible explanation is supported by reciprocal interactions between EM and nerves. ${ }^{5,6,12,37}$ Not only does EM promote neurogenesis, ${ }^{5}$ but in turn the nerves promote angiogenesis and EM growth. ${ }^{6,39} \mathrm{EM}$ can be classified into several subtypes, of which deep infiltrating endometriosis (DIE) seems to be the most aggressive and most challenging to treat due to its invasive nature. ${ }^{5}$ DIE is more painful than other forms of EM, which can be explained by its propensity to invade and extend along the pelvic nerves. ${ }^{2-4}$ DIE can cause ureteral or rectosigmoid strictures and sacral plexus entrapment requiring demanding reconstructive surgeries. ${ }^{3,48}$
Intraneural invasion of major somatic nerves such as the sciatic or obturator nerve prevents complete resection. DIE can also be more challenging to diagnose as it may have no peritoneal manifestation at all ${ }^{36}$ or may present only with peritoneal "pockets," ${ }^{\text {, }}$ probably caused by subperitoneal scarring and retraction.

Possover et al. ${ }^{37}$ were the first to propose a "neural hypothesis," describing a major role of the pelvic nervous system in EM. To support the theory, they correlated common locations of DIE with major components of the pelvic sympathetic system. Although the parasympathetic system might be implicated as well, ${ }^{27}$ other authors have observed a similar distribution of DIE. ${ }^{14,15,52}$

EM is heterogeneously hyperintense on T1-weighted MRI due to blood collections and hypointense from hemosiderin depositions. On T2-weighted MRI, it has a similar heterogeneous appearance. Typical, but very nonspecific, is retraction of surrounding tissue due to scarring. The perineural spread can be visualized as an abnormality extending from the uterus toward the LSP (Figs. 2A and 5A and $\mathrm{B}$ ), which is hyperintense on T2-weighted MRI and avidly enhancing on post-Gd scans. The LSP and branching nerves infiltrated with EM are enlarged, hyperintense 

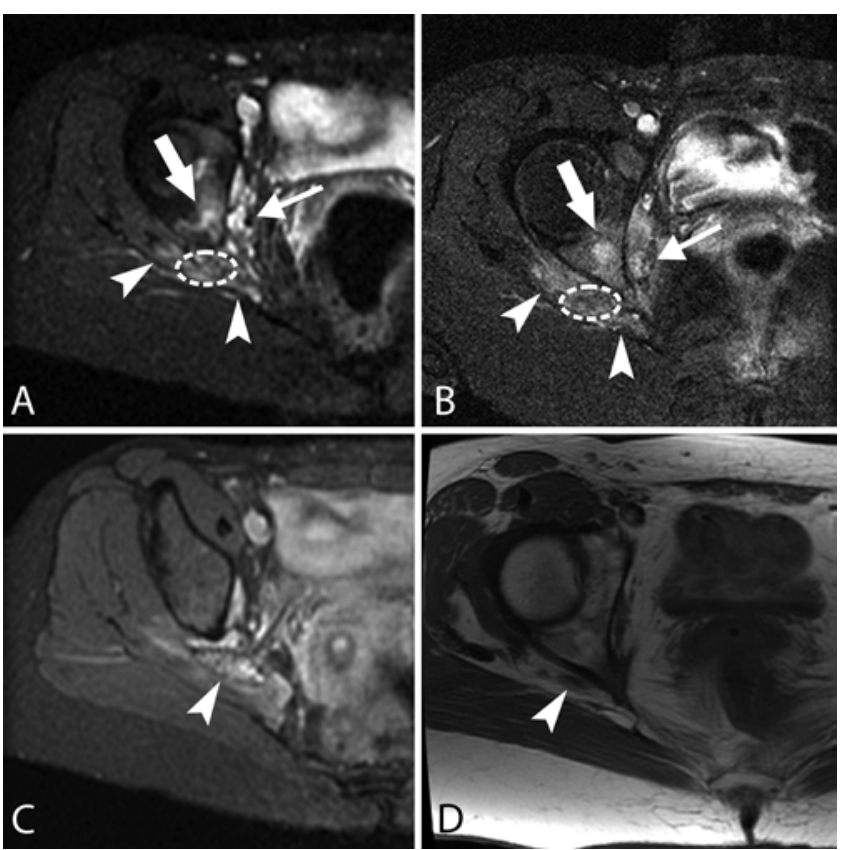

FIG. 4. Case 2. MRI. An axial T2-weighted MR image (A) demonstrates heterogeneously increased signal in the enlarged right sciatic nerve (ellipse). The obturator internus muscle is infiltrated with a heterogeneous hyperintense soft-tissue mass with hemosiderin depositions (thin arrow). The muscle itself and the piriformis muscle (arrowheads) show diffusely increased signal suggestive of denervation. Another nodulus of similar characteristics is observed in the right ischium (thick arrow). The same structures demonstrate prominent heterogeneous enhancement on axial T1-weighted Gd-enhanced MR imaging (B) (thin arrow: obturator internus muscle; thick arrow: ischium; arrowheads: piriformis muscle; ellipse: sciatic nerve). An axial T2-weighted image (C) demonstrates a massively enlarged and infiltrated right sciatic nerve at the sciatic notch (arrowhead). An axial follow-up T1-weighted image (D) obtained 6 years later shows marked improvement of the sciatic nerve enlargement (arrowhead).

on T2-weighted MR images, and heterogeneously enhancing on contrast-enhanced images.

We understand that intraperitoneal seeding with subsequent nerve compression is the most probable explanation for most cases with neural symptoms. A review of the literature revealed several other cases of interest. These can be divided into 2 subgroups: 1) cases with nerve involvement and no peritoneal disease; and 2) cases with intraneural (e.g., intrasciatic) EM with either unspecified or some peritoneal disease. Possover and Chiantera ${ }^{36}$ reported 3 cases of sciatic nerve EM, one of which was intraneural. None of these cases had any peritoneal disease. Pham et al. ${ }^{35}$ reported a case in a patient presenting with sciatic nerve weakness. At the time of presentation, the patient had no peritoneal disease, and on biopsy EM was found in the epineurium. Interestingly, gluteal and pelvic muscles demonstrated denervation, pointing to a more widespread process. Torkelson et $\mathrm{al} .{ }^{46}$ reported 2 cases, one of which had no peritoneal disease and intraneural EM of the sciatic nerve. Ceccaroni et al. ${ }^{13}$ reported another case of sciatic nerve EM and no peritoneal disease. Several authors, however, reported cases of intraneural sciatic nerve EM, which could be explained by perineural spread. .4,30,31,43,56 $^{2}$ Waer et al. ${ }^{51}$ reported a case of EM with perineural spread
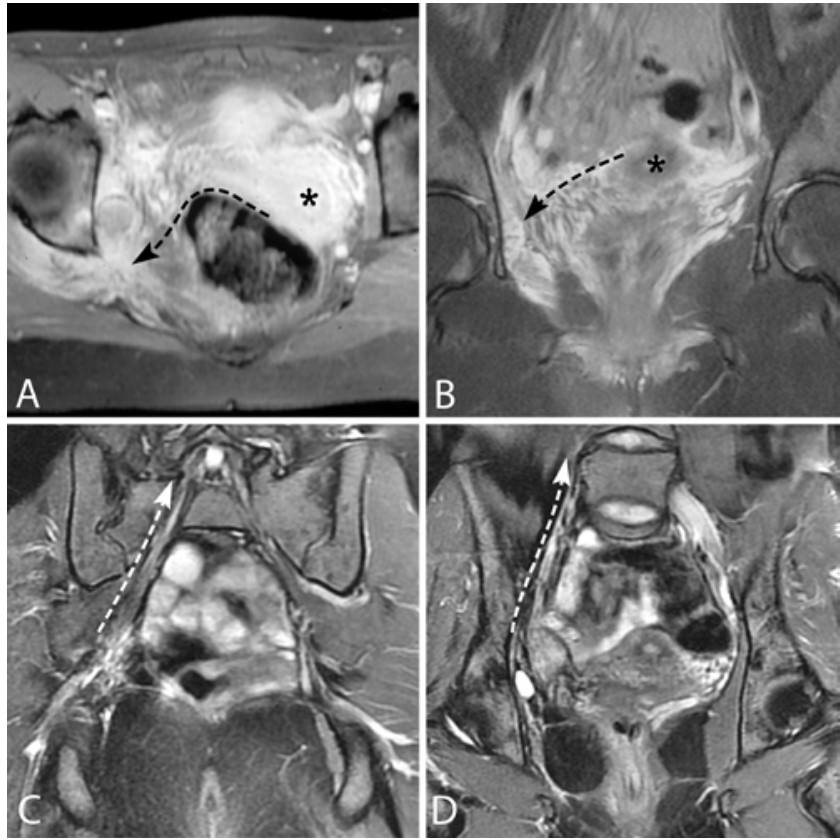

FIG. 5. Outside case. MRI. An axial T1-weighted Gd-enhanced image (A) demonstrates an enhancing abnormality extending from the cervix (asterisk) to the sciatic notch and the sciatic nerve (dashed arrow). A coronal T2-weighted fat-saturated image (B) demonstrates the same hyperintense and heterogeneous abnormality (dashed arrow) extending from the cervix (asterisk). Coronal fat-saturated fast spin echo images ( $C$ and $D$ ) from an MRI examination performed 3 years later show the hyperintense and enlarged right S-1 and L-4 spinal nerves demonstrating signs of perineural spread ( $\mathrm{C}$, dashed arrow, the S-1 spinal nerve; $\mathrm{D}$, dashed arrow, the L-4 spinal nerve).

along the obturator nerve. We wonder if cases of EM with nerve and bone or muscle involvement could be explained by perineural spread along the periosteal and muscle branches. Redwine and Sharpe ${ }^{40}$ reported a case of obturator nerve EM extending to the ilium. A case of sciatic nerve EM that spread to the femur was described by Oei et al. ${ }^{33}$ Also, the second case of sciatic nerve EM reported by Torkelson et al. ${ }^{46}$ had EM in the ischial tuberosity in a pattern that was reminiscent of that described in perineural spread of cancer and in Case 2. ${ }^{9}$ In their series, Possover and Chiantera ${ }^{36}$ reported a case of sciatic nerve EM with extension to the obturator internus muscle-again, a similar pattern to that seen in our case and to that described in perineural cancer spread. ${ }^{8}$ We further hypothesize that cases of conus medullaris EM could be explained as an extension of the same process intradurally along the sacral and lumbar nerve roots, ${ }^{20,44}$ possibly with subsequent intradural seeding ${ }^{19}$ as proposed in perineural spread of prostate cancer..$^{10}$

\section{Limitations}

We understand that our article has several limitations. It is based on 2 individual cases, and further research is needed to confirm perineural spread of EM as an alternative explanation for sciatic nerve EM. We acknowledge that the theory of retrograde menstruation with intraperitoneal seeding first proposed by Sampson ${ }^{7,41}$ is the likely explanation for most cases of sacral plexus EM. We pro- 


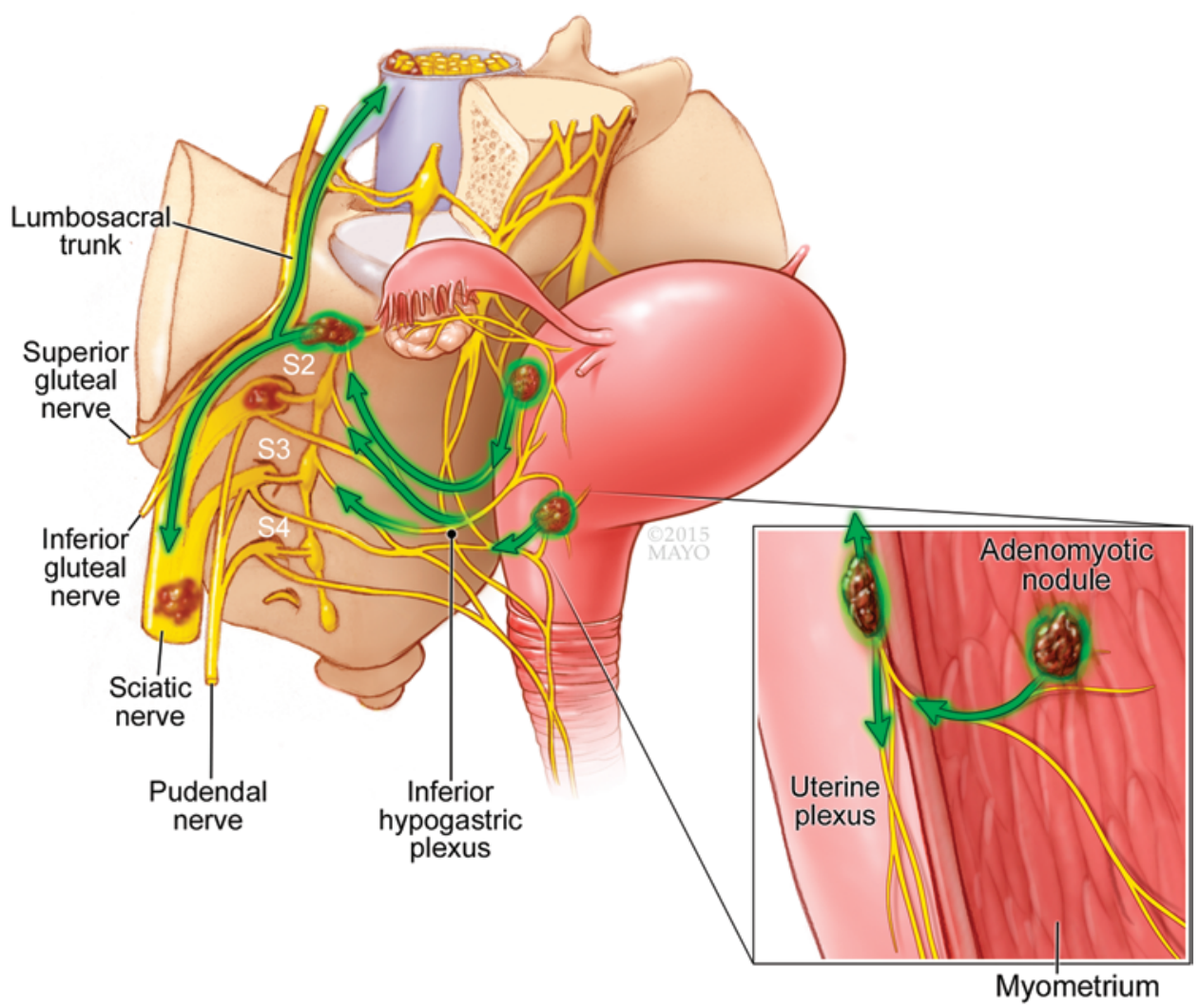

FIG. 6. Illustration of perineural spread of endometriosis. An artistic rendition of perineural spread of endometriosis along the pelvic autonomic nerves to the sacral plexus and further distally to the sciatic nerve or proximally to the spinal nerves. A possible intradural extension along the nerve roots is depicted. Used with permission of the Mayo Foundation for Medical Education and Research. All rights reserved.

vide a secondary explanation applicable to selected cases supported by compelling evidence based on imaging studies and review of the literature. Vercellini et al ${ }^{47}$ reviewed the reported cases of sciatic nerve EM published until 2002 and found that the right sciatic nerve was significantly more involved than the left sciatic nerve. They proposed that this could be explained anatomically as the sigmoid "protects" the left sacral plexus. However, when we used the same methodology, reviewed all cases they referenced, and added all cases published until the time of writing (47 new cases), $13,16,21,23,26,28,29,31,32,34,35,38,42,43,45,49,50,53-55$ we could not confirm their finding-there was no statistically significant difference between the left and right side. We acknowledge other possible explanations such as lymphatic or hematogenous spread, but none of these theories would explain a continuous band of EM extending from the uterus to the LSP as seen in the imaging evidence presented here. Separated, individual lesions (e.g., EM focus in lungs) would be expected with hematogenous or lymphogenous spread. None of our patients had evidence suggestive of such lesions; in addition, this has been excluded in our Case 1 by whole-body PET/CT scanning.

\section{Conclusions}

We described the cases of 2 patients with sciatic nerve EM. We demonstrated that our theory is applicable to other cases reported in the literature. We theorize that both can be explained by perineural spread of EM from the uterus to the sacral plexus along the visceral autonomic nerves. From the plexus, EM can spread proximally to the spinal nerves or distally to the sciatic nerve or pelvic bone and musculature using bone and muscle nerve branches. Such a complete, mechanistic explanation for selected cases of EM presenting with nerve symptoms has not, to our knowledge, been presented until now.

\section{Acknowledgments}

We are very thankful for the contribution of Dr. Caterina Giannini, who initially evaluated the specimen in Case 1. We are very grateful to Drs. Domínguez-Páez and Socolovsky, who provided us with imaging material of the case they previously reported on.

Dr. Capek is supported by European Regional Development Fund-Project FNUSA-ICRC (CZ.1.05/1.1.00/02.0123).

\section{References}

1. Aghion DM, Capek S, Howe BM, Hepel JT, Sambandam S, Oyelese AA, et al: Perineural tumor spread of bladder cancer causing lumbosacral plexopathy: an anatomic explanation. Acta Neurochir (Wien) 156:2331-2336, 2014 [Erratum in Acta Neurochir (Wien) 157:153, 2015]

2. Anaf V, El Nakadi I, De Moor V, Chapron C, Pistofidis G, Noel JC: Increased nerve density in deep infiltrating endometriotic nodules. Gynecol Obstet Invest 71:112-117, 2011

3. Anaf V, El Nakadi I, Simon P, Van de Stadt J, Fayt I, Simonart T, et al: Preferential infiltration of large bowel endome- 
triosis along the nerves of the colon. Hum Reprod 19:9961002,2004

4. Anaf V, Simon P, El Nakadi I, Fayt I, Buxant F, Simonart T, et al: Relationship between endometriotic foci and nerves in rectovaginal endometriotic nodules. Hum Reprod 15:17441750,2000

5. Anaf V, Simon P, El Nakadi I, Fayt I, Simonart T, Buxant F, et al: Hyperalgesia, nerve infiltration and nerve growth factor expression in deep adenomyotic nodules, peritoneal and ovarian endometriosis. Hum Reprod 17:1895-1900, 2002

6. Asante A, Taylor RN: Endometriosis: the role of neuroangiogenesis. Annu Rev Physiol 73:163-182, 2011

7. Burney RO, Giudice LC: Pathogenesis and pathophysiology of endometriosis. Fertil Steril 98:511-519, 2012

8. Capek S, Amrami KK, Howe BM, Spinner RJ: Perineural tumor spread to the muscle: An alternative for muscle metastasis? Clin Anat 28:560-562, 2015 (Letter)

9. Capek S, Howe BM, Froemming AT, Amrami KK, Spinner RJ: Perineural spread in pelvic malignancies can be an alternate explanation for pelvic bony metastases rather than hematogenous spread. A report of two cases. Skeletal Radiol 44:1365-1370, 2015

10. Capek S, Howe BM, Tracy JA, García JJ, Amrami KK, Spinner RJ: Prostate cancer with perineural spread and dural extension causing bilateral lumbosacral plexopathy: case report. J Neurosurg 122:778-783, 2015

11. Capek S, Sullivan PS, Howe BM, Smyrk TC, Amrami KK, Spinner RJ, et al: Recurrent rectal cancer causing lumbosacral plexopathy with perineural spread to the spinal nerves and the sciatic nerve: an anatomic explanation. Clin Anat 28:136-143, 2015

12. Carvalho L, Podgaec S, Bellodi-Privato M, Falcone T, Abrão MS: Role of eutopic endometrium in pelvic endometriosis. J Minim Invasive Gynecol 18:419-427, 2011

13. Ceccaroni M, Clarizia R, Cosma S, Pesci A, Pontrelli G, Minelli L: Cyclic sciatica in a patient with deep monolateral endometriosis infiltrating the right sciatic nerve. J Spinal Disord Tech 24:474-478, 2011

14. Chapron C, Fauconnier A, Vieira M, Barakat H, Dousset B, Pansini V, et al: Anatomical distribution of deeply infiltrating endometriosis: surgical implications and proposition for a classification. Hum Reprod 18:157-161, 2003

15. Chapron C, Santulli P, de Ziegler D, Noel JC, Anaf V, Streuli $\mathrm{I}$, et al: Ovarian endometrioma: severe pelvic pain is associated with deeply infiltrating endometriosis. Hum Reprod 27:702-711, 2012

16. Chauvin C, Azria E, Mahieu-Caputo D, Madelenat P: [Endometriosis of the ischio-rectal excavation at the contact of the sciatic nerve: a case report of neurolysis by pararectal incision.] Gynecol Obstet Fertil 38:142-146, 2010 (Fr)

17. Denton RO, Sherrill JD: Sciatic syndrome due to endometriosis of sciatic nerve. South Med J 48:1027-1031, 1955

18. Domínguez-Páez M, de Miguel-Pueyo LS, Medina-Imbroda JM, González-García L, Moreno-Ramírez V, Martín-Gallego A, et al: [Sciatica secondary to extrapelvic endometriosis affecting the piriformis muscle. Case report.] Neurocirugia (Astur) 23:170-174, 2012 (Span)

19. Duke R, Fawcett P, Booth J: Recurrent subarachnoid hemorrhage due to endometriosis. Neurology 45:1000-1002, 1995

20. Erbayraktar S, Acar B, Saygili U, Kargi A, Acar U: Management of intramedullary endometriosis of the conus medullaris. A case report. J Reprod Med 47:955-958, 2002

21. Floyd JR II, Keeler ER, Euscher ED, McCutcheon IE: Cyclic sciatica from extrapelvic endometriosis affecting the sciatic nerve. J Neurosurg Spine 14:281-289, 2011

22. Hébert-Blouin MN, Amrami KK, Myers RP, Hanna AS, Spinner RJ: Adenocarcinoma of the prostate involving the lumbosacral plexus: MRI evidence to support direct perineural spread. Acta Neurochir (Wien) 152:1567-1576, 2010
23. Hettler A, Böhm J, Pretzsch M, von Salis-Soglio G: [Extragenital endometriosis leading to piriformis syndrome.] Nervenarzt 77:474-477, 2006 (Ger)

24. Hibbard J, Schreiber JR: Footdrop due to sciatic nerve endometriosis. Am J Obstet Gynecol 149:800-801, 1984

25. Howe BM, Amrami KK, Nathan MA, Garcia JJ, Spinner RJ: Perineural spread of cervical cancer to the sciatic nerve. Skeletal Radiol 42:1627-1631, 2013

26. Hughes MS, Burd TA, Allen WC: Post-traumatic catamenial sciatica. Or thopedics 31:400, 2008

27. Kelm Junior AR, Lancellotti CL, Donadio N, Auge AP, Lima SM, Aoki T, et al: Nerve fibers in uterosacral ligaments of women with deep infiltrating endometriosis. J Reprod Immunol 79:93-99, 2008

28. Koga K, Osuga Y, Harada M, Hirota Y, Yamada H, Akahane $\mathrm{M}$, et al: Sciatic endometriosis diagnosed by computerized tomography-guided biopsy and CD10 immunohistochemical staining. Fertil Steril 84:1508, 2005

29. Lacroix-Triki M, Beyris L, Martel P, Marques B: Low-grade endometrial stromal sarcoma arising from sciatic nerve endometriosis. Obstet Gynecol 104:1147-1149, 2004

30. Lemos N, Kamergorodsky G, Ploger C, Castro R, Schor E, Girão M: Sacral nerve infiltrative endometriosis presenting as perimenstrual right-sided sciatica and bladder atonia: case report and description of surgical technique. J Minim Invasive Gynecol 19:396-400, 2012

31. Mannan K, Altaf F, Maniar S, Tirabosco R, Sinisi M, Carlstedt T: Cyclical sciatica: endometriosis of the sciatic nerve. J Bone Joint Surg Br 90:98-101, 2008

32. Motamedi M, Mousavinia F, Naser Moghadasi A, Talebpoor M, Hajimirzabeigi A: Endometriosis of the lumbosacral plexus: report of a case with foot drop and chronic pelvic pain. Acta Neurol Belg [epub ahead of print], 2015

33. Oei SG, Peters AA, Welvaart K, Bode PJ, Fleuren GJ: Aggressive endometriosis in bone. Lancet 339:1477-1478, 1992

34. Papapietro N, Gulino G, Zobel BB, Di Martino A, Denaro $\mathrm{V}$ : Cyclic sciatica related to an extrapelvic endometriosis of the sciatic nerve: new concepts in surgical therapy. J Spinal Disord Tech 15:436-439, 2002

35. Pham M, Sommer C, Wessig C, Monoranu CM, Pérez J, Stoll $\mathrm{G}$, et al: Magnetic resonance neurography for the diagnosis of extrapelvic sciatic endometriosis. Fertil Steril 94:351. e11-351.e14, 2010

36. Possover M, Chiantera V: Isolated infiltrative endometriosis of the sciatic nerve: a report of three patients. Fertil Steril 87:417.e17-417.e19, 2007

37. Possover M, Rhiem K, Chiantera V: The "neurologic hypothesis": a new concept in the pathogenesis of the endometriosis? Gynecol Surg 2:107-111, 2005

38. Possover M, Schneider T, Henle KP: Laparoscopic therapy for endometriosis and vascular entrapment of sacral plexus. Fertil Steril 95:756-758, 2011

39. Possover M, Tersiev P, Angelov DN: Comparative study of the neuropeptide-Y sympathetic nerves in endometriotic involved and noninvolved sacrouterine ligaments in women with pelvic endometriosis. J Minim Invasive Gynecol 16:340-343, 2009

40. Redwine DB, Sharpe DR: Endometriosis of the obturator nerve. A case report. J Reprod Med 35:434-435, 1990

41. Sampson JA: Peritoneal endometriosis due to menstrual dissemination of endometrial tissue into the peritoneal cavity. Am J Obstet Gynecol 14:442-469, 1927

42. Shetty A, Fishwick KT, Rambani R, Acharya S: An unusual case of post-traumatic endometriosis involving the sciatic nerve in the right greater sciatic notch. J Obstet Gynaecol 30:642, 2010

43. Soriano Guillén AP, Mayayo Sinués E, Mir Torres A, Lanzón Laga A: Endometriosis ciática: una causa poco conocida de ciatalgia. Rehabilitación 48:64-67, 2014 


\section{A. C. Siquara de Sousa et al.}

44. Steinberg JA, Gonda DD, Muller K, Ciacci JD: Endometriosis of the conus medullaris causing cyclic radiculopathy. $\mathbf{J}$ Neurosurg Spine 21:799-804, 2014

45. Teixeira AB, Martins WA, d'Ávila R, Stochero L, Alberton L, Bezerra S, et al: Endometriosis of the sciatic nerve. Arq Neuropsiquiatr 69:995-996, 2011

46. Torkelson SJ, Lee RA, Hildahl DB: Endometriosis of the sciatic nerve: a report of two cases and a review of the literature. Obstet Gynecol 71:473-477, 1988

47. Vercellini P, Chapron C, Fedele L, Frontino G, Zaina B, Crosignani PG: Evidence for asymmetric distribution of sciatic nerve endometriosis. Obstet Gynecol 102:383-387, 2003

48. Vercellini P, Viganò P, Somigliana E, Fedele L: Endometriosis: pathogenesis and treatment. Nat Rev Endocrinol 10:261-275, 2014

49. Volpi E, Seinera P, Ferrero A, Dompè D: Laparoscopic neurolysis of the pelvic sciatic nerve in a case of catamenial footdrop. J Minim Invasive Gynecol 12:525-527, 2005

50. Wadhwa V, Thakkar RS, Maragakis N, Höke A, Sumner CJ, Lloyd TE, et al: Sciatic nerve tumor and tumor-like lesionsuncommon pathologies. Skeletal Radiol 41:763-774, 2012

51. Waer P, Samson I, Sinnaeve F, Sciot R, Pans S: Perineural spread of endometriosis along the obturator nerve into the adductor thigh compartment. Jpn J Radiol 30:446-449, 2012

52. Witz CA: Current concepts in the pathogenesis of endometriosis. Clin Obstet Gynecol 42:566-585, 1999

53. Yao S, Liang Y, Jiang H: Cyclic sciatica due to endometriosis of the sciatica nerve: neurolysis with combined laparoscopic and transgluteal approaches. J Minim Invasive Gynecol 21:S133, 2014
54. Yekeler E, Kumbasar B, Tunaci A, Barman A, Bengisu E, Yavuz E, et al: Cyclic sciatica caused by infiltrative endometriosis: MRI findings. Skeletal Radiol 33:165-168, 2004

55. Yoshimoto M, Kawaguchi S, Takebayashi T, Isogai S, Kurata Y, Nonaka S, et al: Diagnostic features of sciatica without lumbar nerve root compression. J Spinal Disord Tech 22:328-333, 2009

56. Zager EL, Pfeifer SM, Brown MJ, Torosian MH, Hackney DB: Catamenial mononeuropathy and radiculopathy: a treatable neuropathic disorder. J Neurosurg 88:827-830, 1998

\section{Disclosure}

The authors report no conflict of interest concerning the materials or methods used in this study or the findings specified in this paper.

\section{Author Contributions}

Conception and design: all authors. Acquisition of data: all authors. Analysis and interpretation of data: all authors. Drafting the article: all authors. Critically revising the article: all authors. Reviewed submitted version of manuscript: all authors. Approved the final version of the manuscript on behalf of all authors: Spinner. Administrative/technical/material support: Capek, Howe, Jentoft. Study supervision: Spinner, Siquara de Sousa, Amrami.

\section{Correspondence}

Robert J. Spinner, Mayo Clinic, Gonda 8-214, 200 First St. SW, Rochester, MN 55905. email: spinner.robert@mayo.edu. 